\title{
Development Trends and Path for China's Civil and Structural Engineering Science and Technology to 2035
}

\author{
Tao Muxuan ${ }^{1}$, Nie Jianguo ${ }^{2}$, Fan Jiansheng ${ }^{3}$, Pan Wenhao ${ }^{1}$, Wang Jiaji ${ }^{1}$, Liu Cheng ${ }^{1}$ \\ 1. Key Laboratory of Civil Engineering Safety and Durability of Ministry of Education of the PRC, Department of Civil Engineering, Tsinghua \\ University, Beijing 100084, China \\ 2. Beijing Engineering Research Center of Steel and Concrete Composite Structures, Tsinghua University, Beijing 100084, China \\ 3. Department of Civil Engineering, Tsinghua University, Beijing 100084, China
}

\begin{abstract}
China's urbanization needs to shift from rapid growth to quality improvement. As a major carrier and symbol of urbanization, civil and structural engineering will become one of the key development methods for China to improve the quality of its urbanization by creating higher quality living environments. China's civil and structural engineering will undergo crucial transformations and will embrace important opportunities in the period between now and the year 2035. This paper provides an overall review of the world-leading technologies in civil and structural engineering fields, summarizes the development directions and trends of civil and structural engineering technologies to 2035, and identifies pending major issues in China's civil and structural engineering, along with their demands for the engineering science and technology. It further outlines the key technologies and development path for civil and structural engineering, and suggests major projects that need to be implemented nationwide for China's civil and structural engineering to 2035 .
\end{abstract}

Keywords: 2035; civil engineering; structural engineering; development trends; key technology; development path; major projects

\section{Introduction}

Civil and structural engineering directly affects economic and social development, and profoundly impacts living environment, urbanization, and even sustainable social development. New-type urbanization was listed as one of the major strategies for China's future development at the central working conference on urbanization; thus, urban and infrastructure developments have become major driving forces for China's future economic and social development. It is necessary for China's urban development to shift from rapid growth to quality improvement. Civil and structural engineering is a major carrier and symbol of urbanization that will constitute one of the key developmental methods for China to improve the quality of urbanization by creating higher standards living environments. China's civil and structural engineering will undergo crucial transformations and will embrace important opportunities between now and the year 2035. A special research team was formed in 2015 based on the recommendations of the Chinese Academy of Engineering (CAE) Academic Divisions of Civil Engineering, Hydraulic Engineering, and Architectural Engineering under the overall framework of the Research on China's Engineering Science and Technology Development Strategy 2035, and was funded by the CAE and National Nat-

Received Date: 9 December 2016; revised date: 21 December 2016

Corresponding author: Tao Muxuan, Key Laboratory of Civil Engineering Safety and Durability of Ministry of Education of the PRC, Department of Civil Engineering, Tsinghua University, Associate Professor. Major research field is steel and concrete composite structures. E-mail: taomuxuan@tsinghua.edu.cn

Funding program: CAE Advisory Project “Research on China's Engineering Science and Technology Development Strategy 2035” (2015-ZD-14) and “Development Strategy of High-Performance Sustainable Structural Engineering” (2015-ZCQ-09); National Natural Science Foundation of China (L1522025)

Chinese version: Strategic Study of CAE 2017, 19 (1): 073-079

Cited item: Tao Muxuan et al. Development Trends and Path for China's Civil and Structural Engineering Science and Technology to 2035. Strategic Study of CAE https://doi.org/10.15302/J-SSCAE-2017.01.011 
ural Science Foundation of China with the goal to investigate the development strategies for China's civil and structural engineering technologies oriented to year 2035. This study shares a few of the research achievements.

\section{World-leading technologies in civil and structural engineering fields}

The development of civil and structural engineering technologies is closely related to the national conditions and the development stage of the country. Thus, countries worldwide vary with respect to the development of these technologies and design concepts. For example, as Japan has suffered from the threat of earthquakes for a long time, it has achieved rapid development in seismic resistance technology, which is considered to be the best globally. Japan's overall technical style and development path differs from those in the United States, and the country enjoys a distinctive rank worldwide. According to the 2015 QS World University Rankings, with respect to the top ten universities in the fields of civil and structural engineering, the universities in Europe and the United States both occupied three positions, while the universities in mainland China and China's Hong Kong, occupied two positions on the list, and the universities in Japan and Singapore both occupied one position. Therefore, although advanced countries such as European ones, the United States, and Japan have traditionally held leading positions in engineering technologies, China's achievements in civil and structural engineering over the past few years also partially reflects its commitment to possess and develop the world-leading technologies in this field.

\subsection{China's massive infrastructure projects promoted innovation of the structural systems and progress in construction technologies of the large complex structures}

The unprecedented and massive infrastructure projects in China have provided unique opportunities for scientific and technological innovation for China's civil and structural engineering. China's self-developed series of new structure technologies, represented by steel-concrete composite structures, largespan space structures, and prestressed structures, enjoy a worldleading position in terms of the overall technical indicators. These include evident advantages such as saving resources, enhanced safety, improved the quality of life, and reduced labor force. In terms of key technologies in design, analysis, and construction of large complex structures and skyscrapers, China has demonstrated multiple key technological achievements with proprietary intellectual property rights and a world-leading position that solved the key technical problems for the entire industry chain, including planning, material, design, construction, and management [1]. These technological achievements realized continuous breakthroughs of technical limits and conventional ideas, and ensured high-level quality construction of China's major landmark projects.

2.2 Design philosophy that focuses on reliability, durability, and life cycle of engineered structures has been preliminarily realized and widely recognized

Significant progress was achieved in reliability theories [2] for civil engineering structures. Based on reliability mathematics [3], a theoretical system for the reliability design for civil engineering structures was developed, and it played a key role in safety and reliability enhancement of civil engineering structures. With rapid social and economic development, the sustainability is facing a crisis worldwide. Thus, China encourages the application of life cycle design theory with the focus on durability of structures to coordinate all processes, including structural design, construction, operation, and management. This direction is becoming one of the most important and cutting-edge research areas both in China and other countries.

2.3 Application of performance-based seismic design, development of innovative technologies for seismic tests, and promotion of large-scale structural earthquake disaster simulation

The earthquake resistance of civil engineering structures was recently characterized by the fastest progress among all areas in this field. Jointly funded by the Federal Emergency Management Agency (FEMA) and the National Science Foundation (NSF), American scientists and engineers proposed a performance-based seismic design concept $[4,5]$ to reach the new heights in the seismic structural design. The Network for Earthquake Engineering Simulation (NEES) initiated by the United States and the Japan-built E-Defense (the world's largest shaking table) has boosted the progress in technologies for structure seismic tests. As the world's most important methods for structural seismic tests, the shake table test and pseudo-dynamic tests have been widely adopted by researchers both in China and other countries. New test technologies, such as online hybrid testing [6], also yielded satisfactory results in revealing the mechanism of complex structural earthquake disasters. In addition, an improved high-performance computational method significantly boosted the transition of analysis and design of earthquake resistant engineering structures towards efficiency and refinement.

\section{Development directions and trends in civil and structural engineering technologies to 2035}

\subsection{High-performance sustainable civil and structural engineering becoming the major trend}

Given the recent massive civil engineering projects in China, 
the field of civil and structural engineering has faced immense challenges, including increasing resource and energy consumption, serious pollution, short service life, low safety and reliability, and weak capability to resist disasters. These challenges significantly hinder China's sustainable social development. From the present to year 2035, it is expected that the issues civil and structural engineering are facing to will shift from structural safety to durability, service life, capability for disaster resistance, and environmental problems that affect materials, resources, and global energy. Therefore, civil engineering structure technologies will capitalize on life-cycle design theories and methods to make substantial progress with a specific focus on the development of high-performance structural engineering to achieve sustainable development [7]. High-performance structural engineering should exhibit different performance under different circumstances or requirements. For example, with respect to the year 2035, it is necessary for China to make significant progress in building great city clusters, developing deep sea engineering, exploring and using new energy resources, storing strategic materials, and developing innovative military defense devices. The civil engineering structures in the fore-mentioned areas are substantial, and thus, complex, super high-rise, and systematic, and more comprehensive and complex performance requirements will be proposed for high-performance sustainable structural engineering.

\subsection{Improving the capability to resist the emergence of multiple disasters as a key issue in the development of civil and structural engineering technologies}

Civil engineering is a double-edged sword. On the one hand, it brings unlimited civilization development to human beings, and on the other hand, it also causes catastrophic disasters known as civil engineering disasters. Therefore, although civil engineering can lead to disasters, it can also be used to prevent and mitigate them. Increasing numbers of natural disasters (such as earthquakes, typhoon, and floods) and man-made disasters (such as explosions, fire, and weapon attacks) led to higher requirements for civil engineering structures in terms of disaster prevention and mitigation. Therefore, as an important research topic for a long-time perspective, the earthquake-resistance of civil engineering structures is still expected to play a key role in future. The design method has shifted from its safety-focusing principle in the past to the widely-accepted performance-based principle in present, and will move towards recoverable and controllable targets. The design philosophy for earthquakeresistance of civil engineering structures still has substantial room for innovation. Meanwhile, the combined effect of the secondary disasters and multiple disasters that originate from then initial disaster will result in new challenges for civil engineering structures in disaster prevention and mitigation. Physical models for multiple disasters and the simulation and control of civil en- gineering structural disasters under global climate change conditions will pose major limitations on this development.

\subsection{Shortage of labor force pushes the transformation forward and upgrades civil and structural engineering}

From the present to year 2035, the overall trends for global economic and social development are as follows: increasingly aging population, continuous reduction of labor force, and rising labor costs. These trends will profoundly impact civil and structural engineering. The traditional pattern for civil and structural engineering will be unable to satisfy new requirements and the priority will be given to the improving productivity. Given rising labor costs, the shortage of labor forces will push the transformation forward and upgrades civil and structural engineering to seek industrial and intelligent development. It is expected that the traditional decentralized, low-level, and inefficient production pattern for both civil and structural engineering will be replaced by modernized, intelligent, and flexible production patterns for manufacturing, transportation, installment, and scientific management by the year 2035 . These factors will significantly improve productivity, speed up construction, reduce engineering costs, and exercise better-controlled engineering quality.

\subsection{Multi-disciplinary and multi-field cooperation promote innovative civil engineering structure technologies}

Civil engineering structure technologies are the old traditional engineering ones with large-scale, inefficient, and labor-cost features that are unable to satisfy the pattern and requirements for economic and social development in the world. It is expected that the civil engineering industry will undergo tremendous changes in its structure and present a brand-new outlook. From the present to the year 2035, civil and structural engineering technologies will be developed such that they are more refined and intelligent, and the multi-disciplinary integration will inject new vitality into traditional civil and structural engineering technologies. Natural integration of advanced material science and civil and structural engineering may lead to the transformation of high-performance civil engineering materials. The integration of advanced automated, IT, and mechanical technologies with civil and structural engineering will make them more automated and intelligent during construction process and significantly improve the extent of industrialization. The integration of advanced control, mechanical, electronic, and network technologies and civil and structural engineering will push forward the sound development of efficient testing methods and health monitoring technologies for civil and structural engineering. In addition, the integration of computer and software engineering technologies and basic mechanics with civil and structural engineering will inject new vitality into high-performance computing. Furthermore, civil and structural engineering technologies will not be limited 
to traditional fields such as buildings, bridges, and tunnels and will also create new points of growth in emerging fields, such as clean energy, ocean engineering, and defense engineering, to drive scientific and technological progress in civil and structural engineering technologies oriented to the year 2035 .

\section{Pending major issues in China's civil and structural engineering and their demands for engineering technologies}

Civil and structural engineering in China is facing severe challenges while seeking sustainable development. This can be attributed to outdated industrial structures, lack of innovative mechanisms, insufficient original theories and methods [1], lack of self-developed CAE software [8], and the failure of the standard system in leading technical innovation. For China to become globalized, safe, sustainable, and intelligent country from the present to the year 2035, it is necessary for civil and structural engineering technologies to first resolve the following issues when seeking for development.

The first demand involves developing high-performance structural engineering technologies to achieve sustainable development. A summary of a strategic consulting project termed the "Development Status and Frontiers of Civil Engineering" that was set up by CAE in 2009 states that China consumes the maximum amount of civil engineering resources and energy globally, and that the civil engineering industry consumes the most energy among all industries in China. With respect to infrastructure projects, China consumes more than half of the world's steel and cement output annually, in which carbon dioxide emissions account for more than $30 \%$ of the total usage. China's massive infrastructure projects also produce a high amount of waste wherein the amount of waste generated in civil engineering industry accounts for more than $30 \%$ of the total urban waste [1]. The prominent constricts of resources and energy, as well as limited environmental carrying capacity, increased requirements for high-performance structural engineering technologies. Highperformance structural engineering refers to civil and structural engineering that exhibits high performance in safety, productivity, usage, environmental protection, durability, maintenance, and significant economic benefits during the life cycle, including planning, design, construction, operation, and demolition. This is a major method for the sustainable development of civil engineering [7].

The second demand involves establishing a well-organized system for disaster prevention and mitigation to considerably reduce the risks of disasters in civil and structural engineering. The results of the strategic consulting project "Development Status and Frontiers of Civil Engineering" set up by the CAE [1] revealed that, although China pays significant attention to disaster prevention and mitigation of civil and structural engineering, it is more difficult to prevent and mitigate the disasters because more people live in centralized areas and accumulate wealth. The increased frequency of disasters in recent years suggests its intensification. In addition, to lower the resources consumption, the population, and the environment, China was forced to explore underground spaces, oceans, and other areas with more severe and complicated natural conditions and higher risks of disasters. Despite considerable efforts in civil and structural engineering studies, the expected targets were not attained as several scientific problems and technical issues remain unresolved. From the present to the year 2035, it is necessary for a globalized China to possess a greater discursive power and play a key role in addressing the major international crisis of disaster prevention. Furthermore, a safe China is required to build social infrastructure projects with strong resistance capability for accidents and disaster. Therefore, it is imperative for China to establish a well-organized system for disaster prevention and mitigation in civil and structural engineering.

The third demand involves establishing a highly modernized and intelligent construction technology system to speed up structural transformation and upgrades in civil and structural engineering. By 2035, it is expected that a highly intelligent China will possess civil and structural engineering technologies that are more modernized, industrialized, and intelligent. With introduction of new approaches, such as IT technology, 3D printing technology, big data processing, and Internet, civil and structural engineering is expected to achieve high-level and intelligent construction that will include significant benefits, such as saving water, energy, time, material, land, and labor force, and promote the concept of green and sustainable construction. Additionally, China will accelerate structural upgrades for civil and structural engineering, and thus traditional concrete structures will face challenges owing to their low energy efficiency, high labor costs, high consumption of resources and energy, and serious environmental pollution. Standardized and industrialized concrete, steel, composite and other structures, that are more capable of satisfying green and low-carbon requirements will be mainly adopted in the structural engineering field.

The fourth demand involves developing innovative theories, methods, and software, and establishing an advanced technological standardization system for civil and structural engineering. Although China has solved various technical issues related to civil engineering during its massive infrastructure projects, it is important to realize that the bases of solving these issues are mostly theories, methods, and software that were initially established by more advanced countries as stated by Ou et al. For example, the theory of steel structure stability, the theory of structural dynamics, and the design method of seismic response spectra that are commonly used in analysis and design of civil engineering were created by researchers from Europe and the United States. Currently, the most advanced methods for structural tests were invented by researchers from other countries. The analysis and computation techniques of civil and structural 
engineering in China are mostly based on CAE software from other countries. Additionally, standards are the major technical basis and principle for civil engineering construction and play a significant role in leading technical directions, ensuring engineering quality and safety, promoting advanced technologies, and boosting key technical competitiveness. However, China's standard system of civil engineering construction is lagging significantly behind in top-level design and compiling mechanisms, and thereby significantly restricts the progressiveness and leading role of standards [7]. Therefore, China can emerge as a civil engineering power only if it develops innovative theories, methods, and software, and establishes an advanced technological standardization system for civil and structural engineering.

\section{Key technologies and development path for civil and structural engineering}

\subsection{Identify key technologies based on technology foresight}

To identify key technologies in civil and structural engineering from the present to the year 2035, two rounds of large-scale technology foresight expert surveys were performed. Prior to the first-round survey, a list of 15 key technologies was determined by seeking opinions from industry experts. The research group shortened the list to 14 based on the results of the first round and delivered the same to experts for the second-round survey. A total of 189 and 196 experts participated in the first and second round surveys, respectively.

Given all the surveys, the comprehensive index of technological significance and prospective applications best reflect its crucial importance. The results of two rounds of surveys are shown in Fig. 1. "Key technologies in new high-performance structural systems," "civil engineering technologies to comprehensively prevent and mitigate disasters," and "life cycle-based technologies for structural design, construction, operation and maintenance" ranked in the top three as they were widely recognized in the two rounds of surveys, and "key technologies in new high-performance structural systems" ranked first in both rounds of surveys. The innovation of structural systems is a core driving force for progress in the structural engineering field, and thus, it should be considered a top priority in the future development of civil engineering. The development of "key technologies in new high-performance structural systems" is an essential method for structural engineering to achieve sustainable development and structural transformation and critical upgrades. Therefore, it should be viewed as a strategic development direction for future civil and structural engineering. Additionally, key technologies to support the application of "key technologies in new highperformance structural systems", "civil engineering technologies to comprehensively prevent and mitigate disasters" and "life

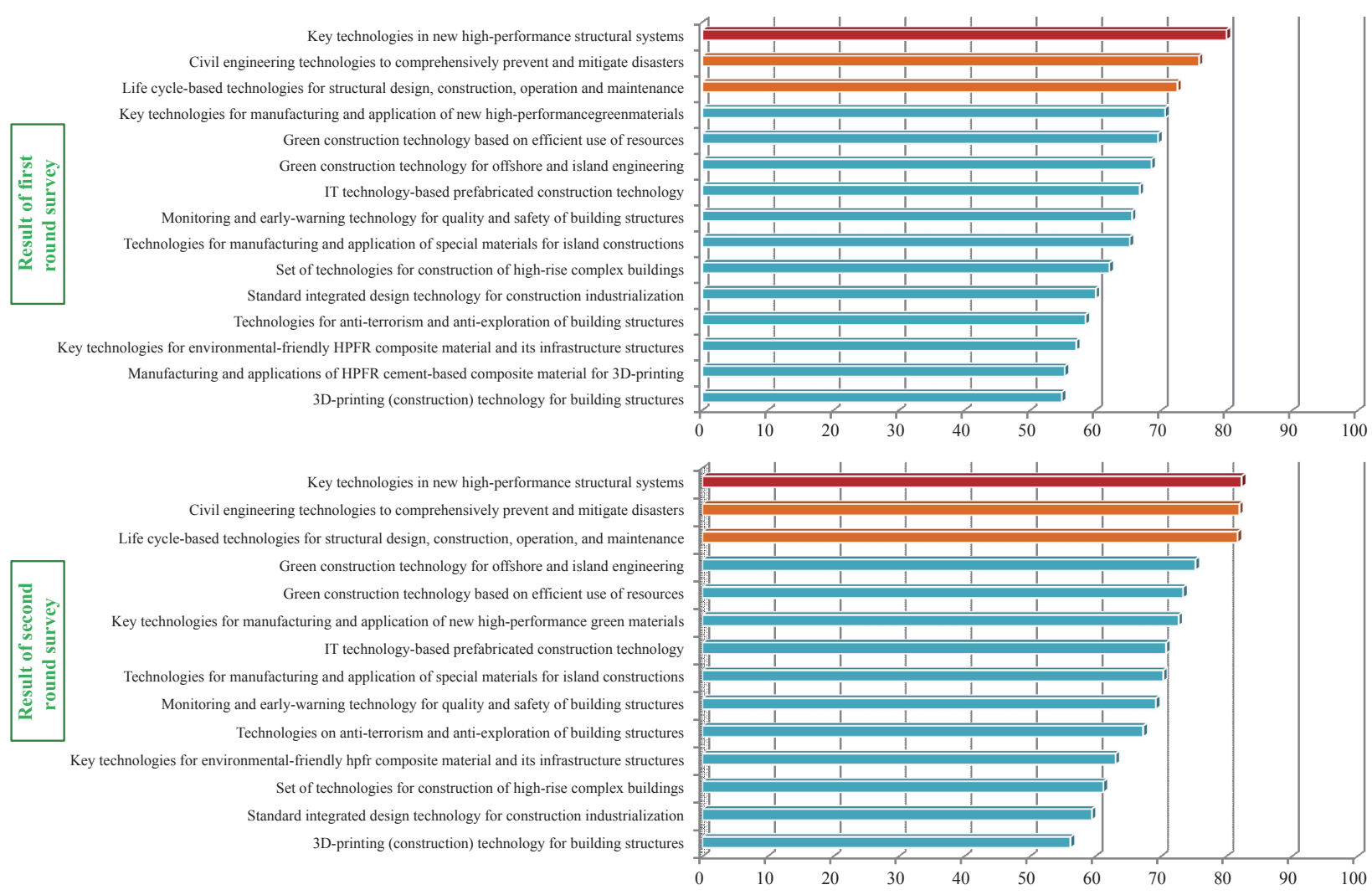

Fig. 1. Comprehensive index of technological significance and its applications. 
cycle-based technologies for structural design, construction, operation and maintenance" will also constitute important research directions in the development of civil and structural engineering.

\subsection{Overall development path of civil and structural engineering technologies}

The overall structure for the development of civil and structural engineering technologies from the present to the year 2035 is shown in Fig. 2. Given the background of multiple scenarios with respect to China's economic and social development from the present to the year 2035, including "strategies for new urbanization," "Belt and Road initiative," "pressure from building sustainable society," and "declining demographic dividends," the development of high-performance sustainable civil and structural engineering technologies presents a key strategy for the development of civil and structural engineering technologies from the present to the year 2035. The development of civil and structural engineering technologies will be performed through multi-disciplinary integration in which modern automatic, IT, mechanical, control, electronics, network, software, and computer technologies will inject new vitality in the development of traditional civil and structural engineering technologies. Advanced civil and structural engineering technologies will be expanded for use in more areas and play a key role in clean energy, ocean engineering, military defense, and strategic storage.

It is expected that by 2035 , civil and structural engineering will achieve greener and lower carbon usage, sustainable development, modernization and intelligence, upgraded industrial structure, and improved living quality. The development path for high-performance sustainable civil and structural engineering technologies is as follows:

\subsubsection{Key objectives}

It is necessary for China to develop high-performance structural systems that exhibit high performance in safety, productivity, usage, durability, maintenance, and economic benefits. Specifically, it should cover stereo comprehensive huge structural systems, intelligent structural systems, generalized composite structural systems, recoverable structural systems, environmental-friendly structural systems, long-life deep sea structural systems, high-performance storage structural systems, and high-performance military defense structural systems.

\subsubsection{Measures and means}

Theories, testing, and computing present the three major

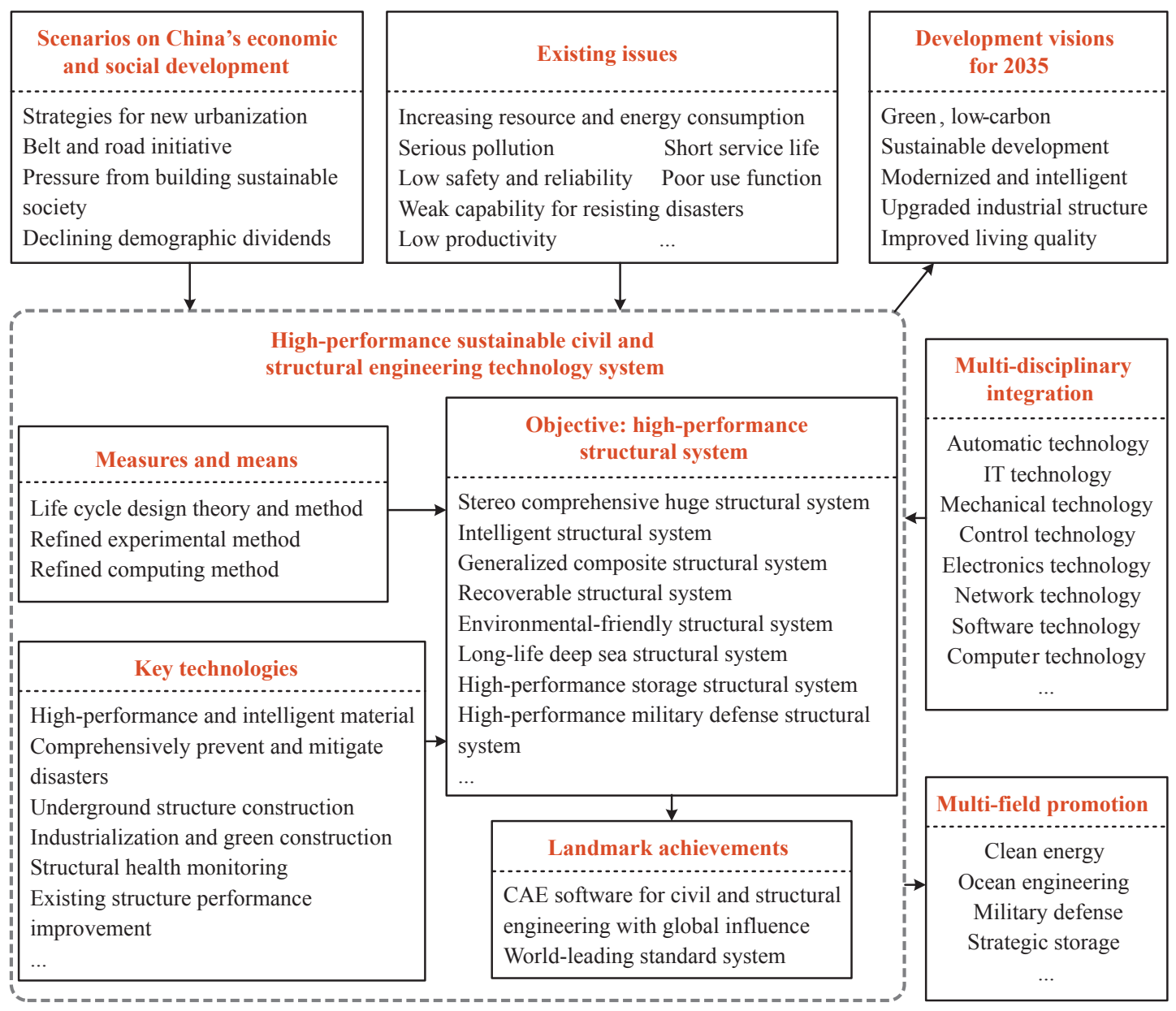

Fig. 2. Overall structure for the development of civil and structural engineering technologies. 
measures that support the research and development of civil and structural engineering technologies. Theoretically, China will set up a structural life cycle design theory system that is compatible with China's engineering structure environment through the innovation of system integration. In terms of testing, China will prioritize new refined experimental methods for civil and structural engineering integrated with modern IT and control technologies, and operate under complex and severe environmental conditions. In terms of computing, China will develop high-performance computing methods for simulation analysis and optimized design of modern civil and structural engineering.

\subsubsection{Key technologies to focus on}

In order to establish a high-performance structural system, China's civil and structural engineering will need to establish clear understanding of the world-leading key technologies in high-performance civil and structural engineering from the present to the year 2035 with a focus on high-performance and intelligent material technology, technology to comprehensively prevent and mitigate disasters, underground structure construction technology, industrialization and green construction technology, structural health monitoring technology, and existing structure performance improvement technology.

\subsubsection{Expected landmark achievements}

CAE software for civil and structural engineering and the standard systems always correspond to landmark achievements that reflect the technical level of civil and structural engineering of the country. However, these are the two factors that restrict China's civil and structural engineering technologies to gain international competitiveness. In order to become a civil engineering power, it is necessary for China to make substantial progress in developing CAE software with proprietary intellectual property rights and high-level standard systems to lead the development of international civil and structural engineering technologies.

\section{Major projects to be implemented on a national level: large-scale and complex civil and structural engineering under extremely severe environment conditions}

It is necessary for China to make significant progress in major areas including stereoscopic cities, deep sea engineering, new energy sources, strategic storage, and military defense. In these areas, civil and structural engineering play a significant role and are complex while facing severe and complex environmental conditions such as natural disasters, extreme climate, and weapon wars. Therefore, it is extremely important for China to implement large-scale and complex civil and structural engineering that can function under extremely severe environmental conditions.
It is necessary for China to develop a number of new structural systems, including a new system for large-scale underground space structures and sky city structures that can be applied to large stereoscopic city clusters; a new system for new large-span bridges, deep sea bases, and long subsea tunnel structures suitable for cross-sea and island connection projects; a new system for new ocean power generation structures and large-scale floating platform and island structures for deep sea resource development; a new system for large granaries and bunkers for national strategic material storage; and a new system for military defense with strong capabilities against weapons and major military target structures. Additionally, China should develop experimental technologies, computational methods, and design theories for large-scale and complex civil and structural engineering that can function under different complex and severe environmental conditions and extreme natural disasters.

By 2035, China will achieve innovative breakthrough upgrades of key technologies for large-scale and complex civil and structural engineering that can operate under complex and severe environmental conditions. These factors will promote the smooth development of civil and structural engineering along with the nature. The achievements will resolve major problems in China's civil and structural engineering and serve a demonstrational role globally.

\section{References}

[1] Academic Divisions of Civil Engineering, Hydraulic Engineering, and Architectural Engineering, Chinese Academy of Engineering. The development status and frontiers of civil engineering [M] Beijing: China Communications Press, 2012. Chinese.

[2] Zhao G F, Jin W L, Gong J X. Reliability theories for engineering structures [M]. Beijing: China Architecture and Building Press, 2000. Chinese.

[3] Li J H. Reliability mathematics [M]. Beijing: China Architecture and Building Press, 1988. Chinese.

[4] Applied Technology Council. NEHRP guidelines for the seismic rehabilitation of building [R]. FEMA Publication 273, Washington, D.C.: Federal Emergency Management Agency, 1997.

[5] Wang M F, Zhou X Y. Performance-based seismic design of building structures [J]. Building Structure, 2003, 33 (3): 59-61. Chinese.

[6] Pan P, Wang T, Nakashima M. Development of online hybrid testing: Theory and applications to structural engineering [M]. International Journal of Productivity \& Performance Management, 2015, 56 (7): 116-121.

[7] Nie J G. The future of structural engineering in China: High-performance structural engineering [J]. China Civil Engineering Journal, 2016, 49 (9): 1-8. Chinese.

[8] Zhong W X, Lu Z J. CAE: Technology for national competitive power and national security $[\mathrm{J}]$. Bulletin of Chinese Academy of Sciences, 2007, 22 (2): 115-119. Chinese. 